\title{
BMJ Open Association between neighbourhood air pollution concentrations and dispensed medication for psychiatric disorders in a large longitudinal cohort of Swedish children and adolescents
}

\author{
Anna Oudin, ${ }^{1}$ Lennart Bråbäck, ${ }^{1}$ Daniel Oudin Åström, ${ }^{1}$ Magnus Strömgren, ${ }^{2}$ \\ Bertil Forsberg ${ }^{1}$
}

To cite: Oudin A, Bråbäck L, Åström D0, et al. Association between neighbourhood air pollution concentrations and dispensed medication for psychiatric disorders in a large longitudinal cohort of Swedish children and adolescents. BMJ Open 2016;6: 010004 .

doi:10.1136/bmjopen-2015010004

- Prepublication history for this paper is available online. To view these files please visit the journal online (http://dx.doi.org/10.1136/ bmjopen-2015-010004).

Received 15 September 2015 Revised 7 March 2016 Accepted 15 April 2016

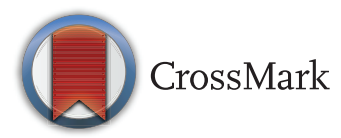

${ }^{1}$ Department of Public Health and Clinical Medicine, Occupational and Environmental Medicine, Umeå University, Umeå, Sweden

${ }^{2}$ Department of Geography and Economic History, Umeå University, Umeå, Sweden

Correspondence to

Anna Oudin;

anna.oudin@envmed.umu.se

\section{ABSTRACT}

Objective: To investigate associations between exposure to air pollution and child and adolescent mental health.

Design: Observational study.

Setting: Swedish National Register data on dispensed medications for a broad range of psychiatric disorders, including sedative medications, sleeping pills and antipsychotic medications, together with socioeconomic and demographic data and a national land use regression model for air pollution concentrations for $\mathrm{NO}_{2}, \mathrm{PM}_{10}$ and $\mathrm{PM}_{2.5}$.

Participants: The entire population under 18 years of age in 4 major counties. We excluded cohort members whose parents had dispensed a medication in the same medication group since the start date of the register. The cohort size was 552221.

Main outcome measures: Cox proportional hazards models to estimate HRs and their $95 \%$ Cls for the outcomes, adjusted for individual-level and group-level characteristics.

Results: The average length of follow-up was 3.5 years, with an average number of events per 1000 cohort members of $\sim 21$. The mean annual level of $\mathrm{NO}_{2}$ was $9.8 \mu \mathrm{g} / \mathrm{m}^{3}$. Children and adolescents living in areas with higher air pollution concentrations were more likely to have a dispensed medication for a psychiatric disorder during follow-up ( $\mathrm{HR}=1.09,95 \%$ Cl 1.06 to 1.12 , associated with a $10 \mu \mathrm{g} / \mathrm{m}^{3}$ increase in $\mathrm{NO}_{2}$ ). The association with $\mathrm{NO}_{2}$ was clearly present in 3 out of 4 counties in the study area; however, no statistically significant heterogeneity was detected.

Conclusion: There may be a link between exposure to air pollution and dispensed medications for certain psychiatric disorders in children and adolescents even at the relatively low levels of air pollution in the study regions. The findings should be corroborated by others.

\section{INTRODUCTION}

Mental disorders are experienced by $10-20 \%$ of all children and adolescents worldwide.

\section{Strengths and limitations of this study}

- Longitudinal cohort approach covering the entire population under 18 in four major counties in Sweden (roughly half of the Swedish population).

- High statistical power allowing for separate analyses in the four counties.

- Register-based data reduce risk of certain bias.

- The outcome, any dispensed medication in the group N05, is a very crude measure of mental health.

These disorders may severely influence children's development, educational attainment and the potential to live fulfilling and productive lives. Air pollution is a complex mixture that most likely affects human health through multiple pathways, and air pollution has been named by the WHO as one of the biggest health threats of our time. ${ }^{1}$ Oberdörster and Utell $^{2}$ first suggested that the brain might be vulnerable to ultrafine ambient particulate matter. Recently, concern has been raised over the effect of air pollution on the central nervous system. ${ }^{3}$ Two early studies linked ambient photochemical oxidants to anxiety symptoms ${ }^{4}$ and depression $^{5}$ in humans in California. Monthly or weekly levels of air pollution were observed to be associated with anxiety symptoms in the Nurses' Health Study, ${ }^{6}$ and with perceived stress in the Veterans Administration Normative Aging Study in the $\mathrm{USA}^{7}$ and a number of studies have observed associations between daily fluctuations in air pollution and mental health outcomes such as depressive symptoms, suicide and emergency calls. ${ }^{8-16}$ Perceived environmental noise and low air quality have been linked to mental health outcomes in adults 
such as depression. ${ }^{17}$ Epidemiological studies have shown that living in areas with elevated concentration of air pollution is linked with decreased cognitive function, ${ }^{18-23}$ lower neurobehavioural testing scores in children, ${ }^{24}$ a decline in neuropsychological development in the first 4 years of life $\mathrm{e}^{25}$ and elevated risk of autism spectrum disorders. ${ }^{26-32}$ Furthermore, children in Spain who attended schools with higher traffic-related air pollution have been observed to have a smaller improvement in cognitive development than children who attended schools with lower traffic-related air pollution. ${ }^{33}$ In a review from 2012 on epidemiological studies on neuropsychological effects of air pollution, the authors conclude that there is evidence for air pollution to be associated with mental development and mental decline. $^{34}$ The National Institute of Environmental Health Sciences/National Institute of Health has convened an expert panel to identify research gaps and priority goals in the field of air pollution and mental disorders such as depression, ${ }^{3}$ and expressed the need for well-designed studies with good data on exposure, outcomes and possible confounders or mediators of effect. ${ }^{3}$ They were highlighting several methodological challenges when investigating air pollution and brain health. For example, parental mental health could influence exposure via socioeconomic status since there are often strong associations between socioeconomy and air pollution levels.

It has been argued that socially disadvantaged people tend to be segregated in relatively deprived areas with a worse environmental quality, ${ }^{35} 36$ and there are often strong socioeconomic gradients in mental health. ${ }^{37}$ Social characteristics may therefore modify the association between air pollution and mental health and also act as a major confounder. There is little consensus on the causal relationship between urbanisation and mental health, but it seems as if urban and rural environments can have pernicious and salutary consequences on mental health. ${ }^{38}$ Factors with strong urban-rural gradients related to the environment such as air pollution concentrations are often neglected as a possible cause of mental health problems. Neighbourhood poverty has, for example, been observed to affect mental health in children, ${ }^{39}$ but there were no adjustments done for neighbourhood air pollution concentrations.

The severe impact of child and adolescent mental health problems on society, together with the plausible and preventable association of exposure to air pollution, deserves special attention. In the present study, the hypothesis was that air pollution may be a risk factor for psychiatric disorders in children and adolescents. Our specific objective was to study associations between neighbourhood residential air pollution concentrations and mental health in children and adolescents. We did so in a longitudinal study, by assessing exposure to air pollution using a nationwide model, in combination with data on dispensed medications for a broad group of psychiatric disorders, and data on potential confounders from nationwide registries in a study population consisting of the entire population of the study area in Sweden.

\section{METHODS}

\section{Study area}

We used a longitudinal study design where the study subjects were all individuals under 18 years of age who at any time during the study period 1 January 2007-31 December 2010 had a registered residential address in any of the four Swedish counties Stockholm, Västra Götaland, Skåne and Västerbotten (figure 1). Stockholm County is located on the eastern coast of Sweden, includes the capital and had a population of just over 2.2 million in early 2015, with a population density of $338 / \mathrm{km}^{2}$. Västra Götaland County is on the western coast and includes the second largest city in Sweden, Gothenburg; it had a population of 1.6 million people in early 2015, with a population density of $68 / \mathrm{km}^{2}$. Skåne County is the southernmost county in Sweden and contains the third largest city, Malmö, with a population of nearly 1.3 million in early 2015 , with a population density of $114 / \mathrm{km}^{2}$. Västerbotten County is located in the Northern part of Sweden, with a total population of just over 260000 in early 2015 , and with a population density of $5 / \mathrm{km}^{2}$. The major part of the population in Västerbotten County lives near the coast, whereas large regions in the inland are very sparsely populated. The four counties are different not just in terms of geographic location, size and population density but also with respect to migration, socioeconomic characteristics, urbanisation and air pollution concentrations.

\section{Swedish National Register data}

We used register data from the Swedish National Board of Health and Welfare on a group of dispensed medication for medicine related to psychiatric diagnoses defined by the Board of Health and Welfare. Data on dispensed medications are available on the entire Swedish population from 1 July 2005. The medication group used as outcome in this study includes any medication with a Swedish ATC code starting with 'N05', hereafter referred to as N05. N05 consists of neuroleptics (antipsychotic medications), ataractics and sleeping pills (a broad group of sedative medications including hydroxyzine and melatonin-based medications). The majority of dispensed N05 medications for children and adolescents are sedative medications and sleeping pills. It should be noted that antidepressants or attention deficit hyperactivity disorder (ADHD) medications are not included in the N05 group. We had access to the number of times each year during follow-up an individual had dispensed an N05 medication (figure 2), but for integrity reasons, we could not obtain data on the exact type of medication within the N05 group. We defined an event as a dispensed N05 medication at least once 

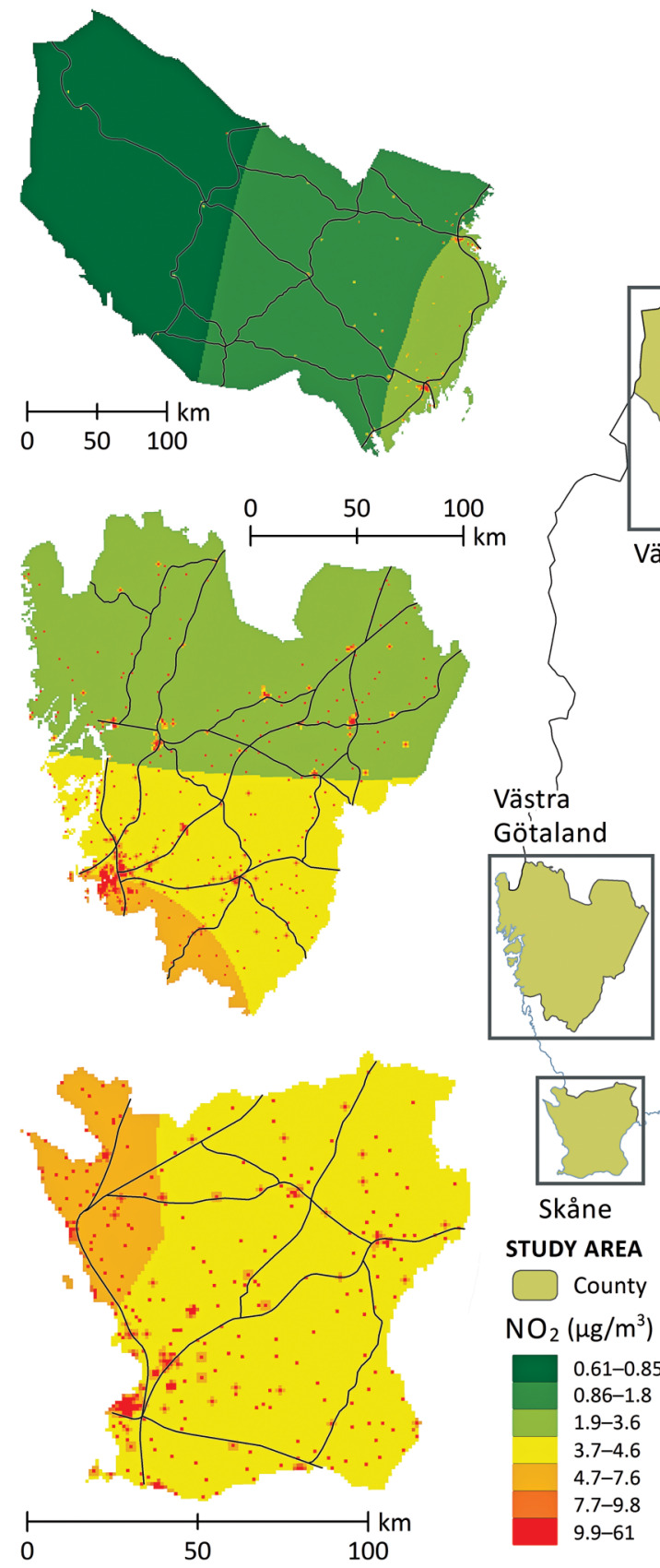

Figure 1 Study area with air pollution concentrations.

during follow-up. Individuals who had a record of an N05 dispensed medication from July 2005 (start date of the register) to 31 December 2006 (the year and a half before start of follow-up) were excluded from the analysis. An event was recorded the first year during follow-up that a N05 medication was dispensed and the event date was set to 1 July (we did not have access to the date each respective year the medication was dispensed). Each cohort member was followed up until an event occurred, loss-to-follow-up (meaning that they had no longer a registered address in the study area), death, 18th birthday or end of follow-up, whichever came first. We used an open cohort approach and continuously included cohort members from date of birth, or individuals moving to the study area from 1 January the year after they moved in. For practical reasons, an individual who moved out of the study area was censored and not included again if he or she moved back. We excluded individuals whose parents had N05 medications dispensed since the start date of the register. The total size of the cohort after exclusions was 896117 individuals. We ran complete data models, meaning that individuals with missing data on any of the variables including in the models were excluded from analysis. The total size of the complete cohort was 552221 individuals (figure 3). 


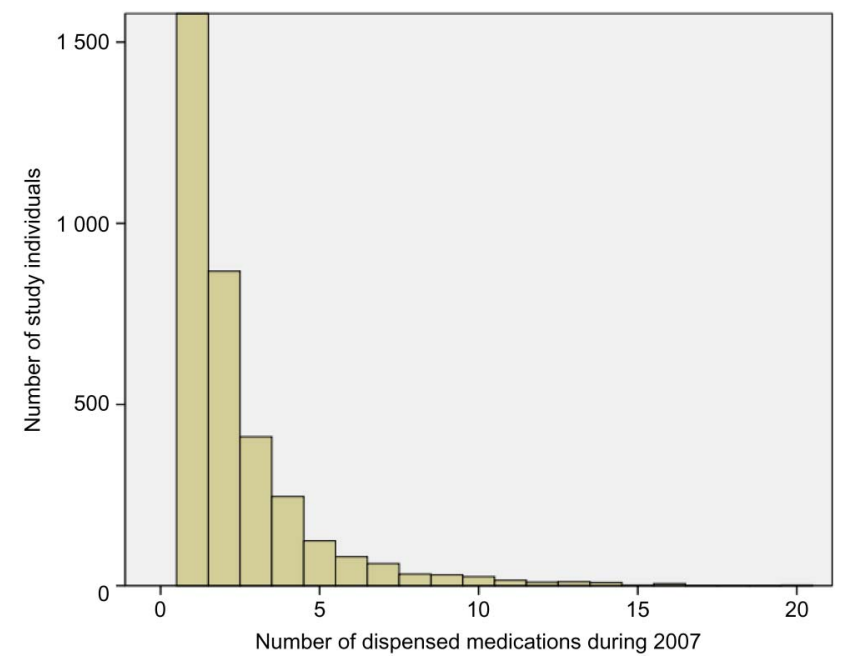

Figure 2 Histogram over the number of dispensed medications during 2007 (6647 in total, 4704=1, $\max =49$ ).

\section{Air pollution exposure assessment}

The Swedish environmental research institute has developed an empirical Land Use Regression model to estimate the urban content of the contribution of nitrogen dioxide and particulate matter. The model is based on the ratio of the urban content contribution, the meteorological parameters and the population distribution. It includes the geographical distribution of the urban contribution, which means that it takes into

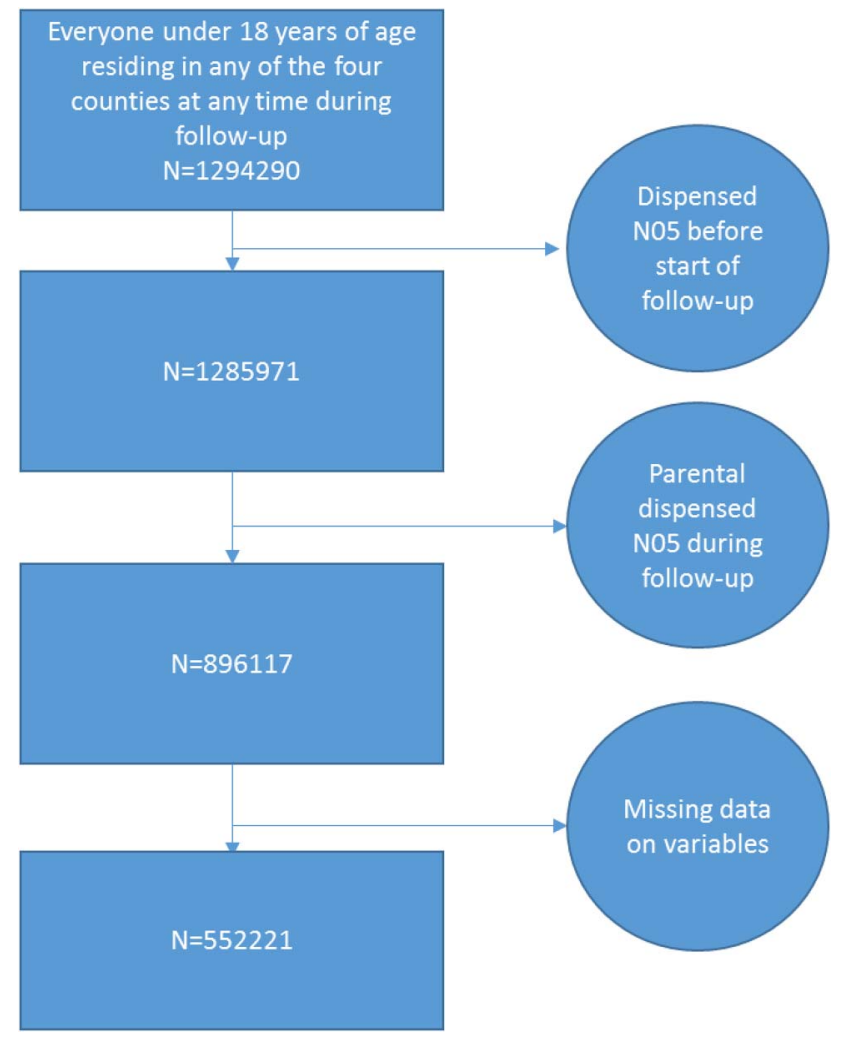

Figure 3 Flow chart. account that the levels are not evenly distributed across a city but related to population density. This model was used together with a model for the regional background levels to calculate the exposure of $\mathrm{NO}_{2}$ and particulates for the entire Swedish population. ${ }^{40}$ We used three measures of exposure to air pollution as a marker of longterm exposure to air pollution, annual means of $\mathrm{NO}_{2}$, $\mathrm{PM}_{10}$ and $\mathrm{PM}_{2.5}$ for the year when the individual was included in the study (any year between 2005 and 2010). The base year of the land use regression model was 2010 , and the estimation of the $\mathrm{PM}_{2.5}$ concentrations was done by using a ratio relation between monitored $\mathrm{PM}_{2.5} / \mathrm{PM}_{10}$ on a yearly and geographical basis. The underlying assumptions were thus that the concentration at study inclusion was a valid marker for long-term exposure, and that the spatial contrasts in exposure during follow-up were fairly constant. In the whole country, 17 sites with measuring data were used. The urban background level of $\mathrm{PM}_{10}$ was estimated with modelled $\mathrm{NO}_{2}$ and measured latitude-specific and season-specific ratios of $\mathrm{PM}_{10} / \mathrm{NO}_{2}$ in the model. For $\mathrm{PM}_{10}$, the cross-validated explained variance ranged between $80 \%$ and $95 \%$ during the year. The model has previously been showed to have fairly good accordance with a dispersion model. ${ }^{41}$ The spatial resolution was $1 \mathrm{~km}^{2}$.

\section{Statistical analysis}

The data were analysed with Cox regression assuming proportional hazards, with time as an underlying variable, resulting in HRs and their 95\% CIs. We studied the exposure as continuous variables, as ratios associated with pollutant increases of $10 \mu \mathrm{g} / \mathrm{m}^{3}$. Tests for proportionality were carried out by visual inspections and by formal testing confirming the assumption of proportional hazards. In the main model, we adjusted for age at the start of follow-up (continuous variable), sex, maternal and paternal education level (four categories), maternal body mass index in early pregnancy (continuous variable) and maternal smoking during early pregnancy (three categories) and for group-level education level (continuous variable). The variables were chosen on the basis of data available in the Swedish National registers. Maternal body mass index and smoking were included in the model more as indicators of socioeconomic status than as potential causes of an association. We defined a group-level variable on socioeconomic status based on data from Statistics Sweden, on Small Areas for Market Statistics (SAMS). There are 9000 SAMS areas in Sweden (6106 in our study area), and the idea is for SAMS to represent homogeneous neighbourhoods. The variable was defined as the proportion of the population in the SAMS area with three or more years of undergraduate studies in the age category 25-65 years.

In an additional analysis, we also adjusted the models for maternal and paternal income. Further, we stratified our analyses on county and sex. 


\section{Sensitivity analyses}

We also ran models where $\mathrm{NO}_{2}$ and $\mathrm{PM}_{10}$ were included simultaneously in the models, and a model where backward selection technique was used to identify the variables that should remain in the model. The variable inclusion criteria were: a $p$ value $<0.05$ or a $20 \%$ change in the HR associated with air pollution.

In addition, we ran models where we excluded SAMS areas with $<1000$ inhabitants $/ \mathrm{km}^{2}$, and a threshold analysis where we only included $\mathrm{NO}_{2}$ concentrations below $15 \mu \mathrm{g} / \mathrm{m}^{3}$. In another sensitivity analysis, we adjusted for population density. Furthermore, we investigated effect modification with respect to age and socioeconomy (at the individual and group levels) by including crossproducts of those variables with the exposure variables in the models. In another sensitivity analysis, follow-up started a year later, 1 January 2008, and individuals with a medication in the registry before that were excluded from the analysis. We also ran age-specific analyses for the age groups $0-4,5-9,10-14$ and $15-18$. Finally, we investigated if patterns of missingness among our variables were approximately the same for cases and noncases and if they were dependent on the outcome or level of exposure. We imputed missing observations using a Markov Chain Monte Carlo approach and reran the main analyses to investigate whether our estimates changed.

SAS V.9.2 software was used to create data sets and run the analyses.

\section{RESULTS}

The HRs regarding $\mathrm{PM}_{10}$ and $\mathrm{PM}_{2.5}$ were very similar. We therefore present only the results for $\mathrm{PM}_{10}$ and $\mathrm{NO}_{2}$. There were in total 18675 individuals who at least once had dispensed N05 during follow-up, with a total number of person-years followed up of 3101756 (table 1). The average length of follow-up was 3.5 years. The number of events per 1000 cohort members was 23 in Västra Götaland, 23 in Västerbotten, 20 in Stockholm and 20 in Skåne (table 1). The agreement between an event in 1 year and an event in subsequent years was not very high; for example, the $\kappa$ statistic calculated for an event in 2007 and 2008 was 0.21 , in 2007 and 2009 was 0.14 , and in 2007 and 2010 was 0.11 . The highest concentrations of $\mathrm{NO}_{2}$ were found in Stockholm (yearly median: $8.3 \mu \mathrm{g} / \mathrm{m}^{3}$ ) and the highest levels of $\mathrm{PM}_{10}$ were found in Skåne (yearly mean median: $15.8 \mu \mathrm{g} / \mathrm{m}^{3}$; table 1). The correlation between $\mathrm{NO}_{2}$ and $\mathrm{PM}_{10}$ was, due to the modelling of $\mathrm{PM}_{10}$, high, and ranged between 0.83 (Västerbotten), 0.97 (Skåne) and 0.98 (Stockholm and Västra Götaland). No formal statistical testing was done of the differences between cohort members with and without an event during follow-up, but the mean concentration of $\mathrm{NO}_{2}$ or $\mathrm{PM}_{10}$ did not seem to differ much between individuals with and without an event of dispensed N05 during follow-up (table 2). The age at inclusion among those who had a dispensed medication was higher than among those without an event of dispensed N05 during follow-up. Maternal body mass index was similar between the two groups, as was the group-level variable on socioeconomy (proportion with high education in the SAMS area). There were some differences with respect to maternal and paternal education levels and maternal smoking during pregnancy between individuals who dispensed medication and individuals who did not (table 2). The size and direction of the correlation coefficients between air pollution concentrations and group-level education were heterogeneous across municipalities in the study area (results not shown). Adjusting for parental income only marginally changed the results (results not shown).

The HR in association with a $10 \mu \mathrm{g} / \mathrm{m}^{3}$ increase in $\mathrm{NO}_{2}$ adjusted for age at the start of follow-up, sex, maternal and paternal education, maternal body mass index in early pregnancy, maternal smoking during early pregnancy and group-level education levels was 1.09 (95\% CI 1.06 to 1.12; table 3 ). The corresponding HR associated with a $10 \mu \mathrm{g} / \mathrm{m}^{3}$ increase in $\mathrm{PM}_{10}$ was 1.04 (95\% CI 1.00 to 1.08). The correlation between $\mathrm{NO}_{2}$ and $\mathrm{PM}_{10}$ was too high for them to be included simultaneously in the model, because $\mathrm{NO}_{2}$ was one of the predictors of urban background $\mathrm{PM}_{10}$ in the $\mathrm{PM}_{10}$ model. When using the backward selection technique to identify what variables should be included in the model, all variables remained in the model due to their low $\mathrm{p}$ values, except the group-level SES variable that had a $p$ value $>0.20$. The estimates with and without that variable included were very similar (results not shown). The crude HRs were close to one (no association), and the association appeared when adjusting for age. The other variables did not seem to have any substantial influence on the estimates (results not shown). The associations seemed heterogeneous across the four counties (table 3 and

Table 1 Description of the four counties in the study area

\begin{tabular}{|c|c|c|c|c|c|c|}
\hline County & Events & $\begin{array}{l}\text { Cohort } \\
\text { size }\end{array}$ & $\begin{array}{l}\text { Person-time } \\
\text { (years) }\end{array}$ & $\begin{array}{l}\text { Events } \\
\text { per } 1000 \\
\text { persons }\end{array}$ & $\begin{array}{l}\text { Annual mean } \mathrm{NO}_{2} \\
50 \mathrm{th}, 5 \mathrm{th}-95 \mathrm{th} \\
\text { percentile }\left(\mu \mathrm{g} / \mathrm{m}^{3}\right)\end{array}$ & $\begin{array}{l}\text { Annual mean } \mathrm{PM}_{10} \text { 50th, } \\
5 \text { th-95th percentile } \\
\left(\mu \mathrm{g} / \mathrm{m}^{3}\right)\end{array}$ \\
\hline Stockholm & 7346 & 360683 & 1235018 & 20.4 & $8.3(3.7-21.5)$ & 8.7 (3.8-21.5) \\
\hline Västra Götaland & 6004 & 270398 & 948035 & 22.2 & 7.7 (3.1-24.8) & $14.2(9.4-24.8)$ \\
\hline Skåne & 4248 & 218064 & 758504 & 19.5 & $7.4(4.0-23.1)$ & $15.8(11.2-33.5)$ \\
\hline Västerbotten & 1077 & 46972 & 165599 & 22.9 & $2.3(0.8-15.5)$ & $5.7(3.6-9.0)$ \\
\hline
\end{tabular}


figure $4 \mathrm{~A}, \mathrm{~B})$, at least for the association with $\mathrm{PM}_{10}$ $(\mathrm{p}=0.001)$. For $\mathrm{NO}_{2}$, the $\mathrm{p}$ value for effect modification was 0.24 . For example, the association with a $10 \mu \mathrm{g} / \mathrm{m}^{3}$ increase in $\mathrm{NO}_{2}$ was quite similar in Stockholm, Västra Götaland and Västerbotten (HRs of 1.13, 1.11 and 1.13, respectively), whereas there was no evident association $(\mathrm{HR}=1.03)$ in Skåne (table 3 and figure 4A,B). The HRs associated with a $10 \mu \mathrm{g} / \mathrm{m}^{3}$ increase in $\mathrm{PM}_{10}$ were quite similar in Stockholm and Västra Götaland (1.23 and 1.18, respectively), 1.00 in Skåne and 1.89 in Västerbotten. The high estimate in Västerbotten is uncertain, a contributing factor that may be low statistical power to detect differences. The estimates seemed similar among boys and girls (table 3 ), and the $\mathrm{p}$ value for effect modification was 0.30 for $\mathrm{NO}_{2}$ and 0.82 for $\mathrm{PM}_{10}$.

\section{Sensitivity analyses}

When excluding the more rural areas (population density $<1000$ inhabitants $/ \mathrm{km}^{2}$ ), the size of the Stockholm cohort was barely affected, whereas the size of the Västra Götaland and Skåne cohorts was less than half the original size. The HRs of those three cohorts remained stable (table 3). Regarding Västerbotten, only a third of the original cohort remained, and the size of the HRs completely changed and the loss in precision was substantial (table 3). In the threshold analysis, where we excluded neighbourhoods with concentrations above $15 \mu \mathrm{g} / \mathrm{m}^{3}$, the size of the cohorts did not change much due to the low levels of air pollution in general, and consequently neither did the HRs. However, the HR in association with the $10 \mu \mathrm{g} / \mathrm{m}^{3}$ increase in $\mathrm{NO}_{2}$ in Skåne was 1.16 (95\% CI 1.02 to 1.33), which is different from the overall HR of 1.02. When adjusting for population density, the models did not perform very well (results not shown). There was no effect modification by age or socioeconomic status (results not shown). Starting follow-up a year later only marginally altered the effect estimates (results not shown). The age-specific HRs revealed no evident age trends (results not shown). Including the highly correlated $\mathrm{NO}_{2}$ and $\mathrm{PM}_{10}$ in a twopollutant model changed the overall estimate upwards for $\mathrm{NO}_{2}$ to 1.18 (95\% CI 1.12 to 1.24) and downwards for $\mathrm{PM}_{10}$ to 0.90 (95\% CI 0.84 to 0.95 ).

The patterns of missingness among variables were approximately the same for cases and non-cases and were not dependent on the outcome or exposure level. Imputing missing data yielded similar results as the main model (results not shown).

\section{DISCUSSION}

\section{Principal findings}

In this longitudinal study of Swedish children and adolescents, neighbourhood air pollution concentration

Table 2 Descriptive statistics of explanatory variables stratified on the outcome

\begin{tabular}{|c|c|c|c|c|c|}
\hline & & $\begin{array}{l}\text { Dispensed N05 } \\
\text { during follow-up } \\
\text { Mean (SD) }\end{array}$ & $\begin{array}{l}\text { Missing } \\
\text { N (\%) }\end{array}$ & $\begin{array}{l}\text { Not dispensed N05 } \\
\text { during follow-up } \\
\text { Mean (SD) }\end{array}$ & $\begin{array}{l}\text { Missing } \\
\text { N (\%) }\end{array}$ \\
\hline $\mathrm{NO}_{2}$ & & $9.7(7.0)$ & $35(0.2)$ & $9.8(7.1)$ & $7857(0.9)$ \\
\hline $\mathrm{PM}_{10}$ & & $13.6(5.9)$ & $35(0.2)$ & $13.7(6.2)$ & $7857(0.9)$ \\
\hline Age the start of follow-up & & $11.1(6.0)$ & $0(0)$ & $7.4(5.8)$ & $0(0)$ \\
\hline Maternal BMI early pregnancy & & $23.9(4.3)$ & 8467 (45.3) & $23.9(4.0)$ & $283811(32.4)$ \\
\hline \multirow{2}{*}{$\begin{array}{l}\text { Proportion with high* education } \\
\text { level }\end{array}$} & & $0.22(0.12)$ & $1(0)$ & $0.23(0.13)$ & $154(0)$ \\
\hline & & $\mathrm{N}(\%)$ & & N (\%) & \\
\hline Sex & Girls & $10068(54)$ & & $426669(49)$ & \\
\hline \multirow{5}{*}{ Maternal education level } & Missing & $1598(9)$ & & $79050(9)$ & \\
\hline & $\leq 9$ years & 2075 (12) & & $79627(12)$ & \\
\hline & $>9$ to $\leq 12$ years & $8307(49)$ & & $351721(44)$ & \\
\hline & $>12$ to $<16$ years & $5137(30)$ & & $272618(34)$ & \\
\hline & $\geq 16$ years & $1558(9)$ & & $94426(12)$ & \\
\hline \multirow[t]{5}{*}{ Paternal education level } & Missing & 2109 (11) & & 90477 (10) & \\
\hline & $\leq 9$ years & 2775 (17) & & $100911(13)$ & \\
\hline & $>9$ to $\leq 12$ years & $8248(50)$ & & 369703 (47) & \\
\hline & $>12$ to $<16$ years & $3795(23)$ & & $209140(27)$ & \\
\hline & $\geq 16$ years & $1748(11)$ & & $107211(14)$ & \\
\hline \multirow{4}{*}{$\begin{array}{l}\text { Maternal smoking during } \\
\text { pregnancy }\end{array}$} & Missing & & & & \\
\hline & Non-smokers & $12213(79)$ & & 645369 (89) & \\
\hline & $\begin{array}{l}\text { 1-9 cigarettes per } \\
\text { day }\end{array}$ & $1926(13)$ & & $54361(7)$ & \\
\hline & $\begin{array}{l}\geq 10 \text { cigarettes per } \\
\text { day }\end{array}$ & $1231(8)$ & & $25584(4)$ & \\
\hline
\end{tabular}


Table $3 \mathrm{HRs}$ and their 95\% Cls for an event (dispensed N05 medications during follow-up) in association with a $10 \mu \mathrm{g} / \mathrm{m}^{3}$ increase in $\mathrm{NO}_{2}$ and $\mathrm{PM}_{10}$, adjusted for individual-level and group-level characteristics

\begin{tabular}{|c|c|c|c|c|}
\hline & & $\begin{array}{l}\text { Number of observations } \\
\text { in total/in analysis/events }\end{array}$ & $\begin{array}{l}\mathrm{NO}_{2} \\
\mathrm{HR}(95 \% \mathrm{Cl})\end{array}$ & $\begin{array}{l}\mathrm{PM}_{10} \\
\mathrm{HR}(95 \% \mathrm{Cl})\end{array}$ \\
\hline All cohort* & & 896 117/552 221/9264 & $1.087(1.055$ to 1.121$)$ & 1.038 (1.003 to 1.076$)$ \\
\hline \multirow[t]{4}{*}{ Stratified by county } & Stockholm & 360 683/209 589/3455 & 1.129 (1.068 to 1.194$)$ & 1.227 (1.123 to 1.340$)$ \\
\hline & Västra Götaland & $270398 / 173210 / 3066$ & 1.106 (1.056 to 1.158$)$ & 1.175 (1.091 to 1.266$)$ \\
\hline & Skåne & 218 064/140 385/2290 & $1.019(0.945$ to 1.1097$)$ & 0.995 (0.927 to 1.067$)$ \\
\hline & Västerbotten & 46 972/29 500/467 & $1.130(0.930$ to 1.373$)$ & 1.894 (1.128 to 3.180$)$ \\
\hline \multirow[t]{2}{*}{ Stratified by sex } & Girls & 436 737/268 943/4775 & 1.080 (1.035 to 1.127$)$ & 1.040 (0.991 to 1.093$)$ \\
\hline & Boys & 459 380/283 278/4489 & $1.092(1.045$ to 1.141$)$ & $1.033(0.9991$ to 1.093$)$ \\
\hline \multirow{4}{*}{$\begin{array}{l}\text { Exclude SAMS areas } \\
\text { with a population } \\
\text { density of }<1000 / \mathrm{km}^{2}\end{array}$} & Stockholm & $294728 / 167711 / 2769$ & 1.108 (1.043 to 1.177$)$ & 1.180 (1.073 to 1.297$)$ \\
\hline & Västra Götaland & 122 083/72 773/1288 & 1.071 (1.010 to 1.136$)$ & 1.110 (1.007 to 1.225$)$ \\
\hline & Skåne & $111000 / 66$ 235/1108 & 0.890 (0.808 to 0.981$)$ & 0.891 (0.812 to 0.977$)$ \\
\hline & Västerbotten & 13 824/8803/142 & 0.853 (0.609 to 1.193$)$ & $1.127(0.382$ to 3.25$)$ \\
\hline \multirow[t]{4}{*}{ Concentrations $<15 \mu \mathrm{g} / \mathrm{m}^{3}$} & Stockholm & 303 380/177 831/2919 & 1.179 (1.053 to 1.321$)$ & 1.401 (1.187 to 1.652$)$ \\
\hline & Västra Götaland & $215300 / 142$ 031/2494 & 1.107 (0.990 to 1.238$)$ & 1.194 (0.873 to 1.634$)$ \\
\hline & Skåne & 179 700/119 365/1974 & 1.150 (1.003 to 1.319$)$ & $0.775(0.475$ to 1.266$)$ \\
\hline & Västerbotten & $43694 / 27$ 154/423 & $1.124(0.891$ to 1.419$)$ & 1.78 (0.889 to 3.357$)$ \\
\hline a $10 \mu \mathrm{g} / \mathrm{m}^{3}$ increase in with a $10 \mu \mathrm{g} / \mathrm{m}^{3}$ i & . & 6). The & $\begin{array}{l}\text { crease in } \mathrm{NO}_{2} \text { was } 1.013 \\
\text { for individual-level, but no } \\
\text { h a } 10 \mu \mathrm{g} / \mathrm{m}^{3} \text { increase in }\end{array}$ & $\begin{array}{l}5 \% \mathrm{Cl} 0.993 \text { to } 1.034) \text { and } \\
\text { roup-level, characteristics } \\
\mathrm{I}_{10} \text { was } 1.041(95 \% \mathrm{Cl}\end{array}$ \\
\hline
\end{tabular}

was associated with dispensed medications for certain psychiatric disorders, after adjusting for individual-level and group-level characteristics. The association was present in three out of four counties within Sweden. To put our findings in perspective, the association seemed to be present even at annual levels of $\mathrm{NO}_{2}$ lower than $15 \mathrm{\mu g} / \mathrm{m}^{3}$, which can be compared with the WHO guideline and EU air quality standard of $40 \mu \mathrm{g} / \mathrm{m}^{3}$. However, a finer spatial resolution would have resulted in a wider concentration range especially for $\mathrm{NO}_{2}$. This is one of a small number of studies to consider the association between air pollution and mental health, and the first to do so in children. There are several studies suggesting associations between air pollution and autism spectrum disorders ${ }^{26-32}$ and cognitive function in children, ${ }^{23-25} 33$ and this study adds to evidence from them that air pollution may have detrimental effects on the brains of children and adolescents. Furthermore, this is the first study to use a whole population, and to use nationwide register-based data on dispensed medications as an indicator for mental health. Most of the existing evidence for a link between air pollution and mental health comes from short-term studies in adults, where daily fluctuations in air pollution concentrations are compared with the daily number of mental health events or symptoms. ${ }^{8-16}$ Furthermore, associations between longer term exposure to air pollution and anxiety and stress were recently reported in two ageing cohorts. ${ }^{6} 7$

\section{Limitations and strengths of the study}

There are some weaknesses and strengths of the study that should be mentioned. First, any dispensed medication in the group N05 is a very crude measure of mental health. N05 consists of neuroleptics (antipsychotic medications), ataractics and sleeping pills (a broad group of sedative medications including hydroxyzine and melatonin-based medications). Furthermore, the N05 group of medications includes antipsychotic medications, which most often are used for children with acute psychosis, children who are aggressive and acting out, children with severe neuropsychiatric disorders, children with strong anxiety or children where a bipolar condition is suspected. The majority of medications dispensed in the N05 group, however, concern children with different states of anxiety and children to whom sleeping pills are prescribed. The range of mental health problems in individuals with an event during follow-up may thus vary from mild to very severe. Also, the accordance (kappa-values) between a dispensed medication consecutive years was generally low. A dispensed medication for an individual a certain year thus did not necessarily indicated a high probability to dispense a medication the following year. This may indicate that the outcome measure as a marker of general mental health could be questioned. Access to more detailed data on type of dispensed medications would have been desirable, but we did not have access to such data. Given the results of this study, we hope to be able to get access to detailed Swedish register data on dispensed medications in the future. Moreover, we decided to dichotomise the outcome, although we could have used the number of dispensed medications per year as a continuous outcome to get a better estimate of a potential dose-response association. We decided against that 

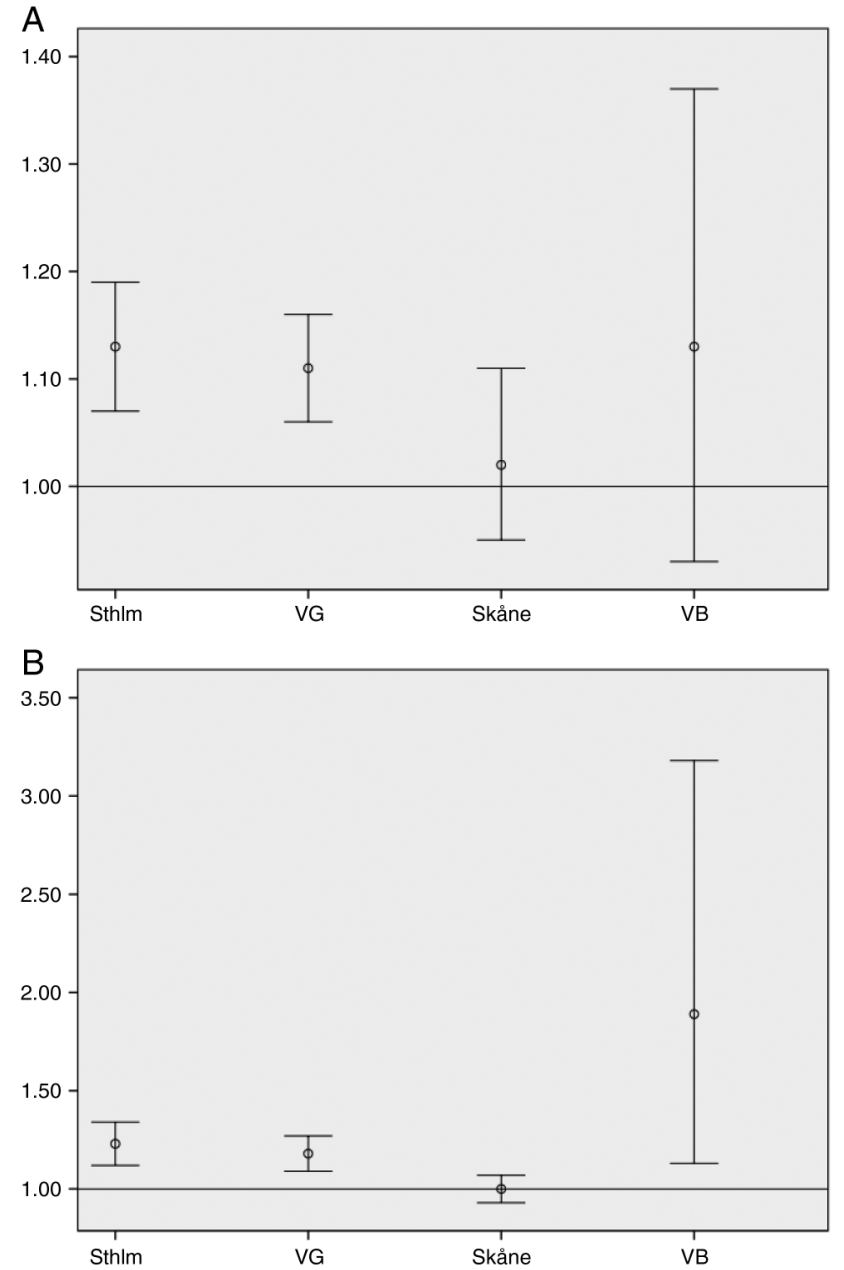

Figure $4 \mathrm{HRs}$ and their $95 \%$ Cls for a dispensed N05 medication during follow-up in association with a $10 \mu \mathrm{g} / \mathrm{m}^{3}$ increase in $\mathrm{NO}_{2}(\mathrm{~A})$ and $\mathrm{PM}_{10}(\mathrm{~B})$ in Stockholm County (Sthlm), Västra Götaland County (VG), Skåne County (Skåne) and Västerbotten County (VB).

since the distribution of the number of dispensed medications was much skewed, with some outliers that seemed unrealistic. Despite the crude measure of mental health in this study, we consider the outcome to be an indicator for mental health in children and adolescents in general. A major strength of the data is that they cover the entire population; thus, the whole population of the study area can be seen as a cohort. We have access to register-based data, where dispensed medications of all Swedes are registered. Selection bias and recall bias therefore do not have to be considered in our setting. Another strength of this study is the longitudinal approach, which increases the validity of the results compared to cross-sectional studies. All individuals with an event 1.5 years before start of follow-up (1 January 2007) were excluded. It would have been desirable to base the exclusion criteria on the lifetime history of dispensed medications, but the register for dispensed medications did not start until 1 July 2005; thus, no data on earlier dispensed medications were available. Individuals with a dispensed medication the year and a half before start of follow-up were excluded from the analysis, but the agreement between a dispensed medication subsequent years was rather low. Therefore, an unknown proportion of the events are not incident events. The study is therefore prone to some of the limitations of a cross-sectional study; for example, reverse causation may be an explanation of our findings. However, delaying follow-up to 1 January 2008 and the sensitivity analyses restricting the sample to only urban areas do not suggest reverse causation to be a major explanation of our findings.

As expected, individuals who had been dispensed N05 during follow-up were much more likely to have parents who had been dispensed the same medication since the start date of the register (eg, 36\% of the mothers compared to $22 \%$ of the mothers for individuals who had not been dispensed N05 during follow-up). We excluded children whose parents had been dispensed a medication for N05 for several reasons: (1) parental mental health problems might influence where the family resides, and therefore also the pollution levels, (2) parental inclination to dispense medication is correlated with children's dispensed medication and (3) parental mental health problems may directly influence children's mental health and an eventual association with air pollution may therefore be explained by the parental mental health status. Adjusting for parental medication for N05 is therefore not straightforward, and we decided to exclude these individuals to get 'cleaner' data, although this might have resulted in an underestimation of the true effect, as well as in a decreased generalisability. Despite that, we consider the exclusion of parents with a dispensed N05 medication to be one of the major strengths of the study.

Exposure measurement error should be considered in our study. We used neighbourhood exposure models with the resolution $1 \mathrm{~km}^{2}$. Exposure contrasts within cities are therefore smoothed out in our data, which may have led to an underestimation of risk. However, the model has been validated, and we were able to use the same model in all four counties within Sweden, which is a major advantage. We used annual mean pollutant concentrations at the home address for the year of study inclusion as a marker for long-term exposure to air pollution. The modelled concentrations were based on the year 2010. The underlying assumption of this study is thus that spatial contrasts in pollutant concentrations were rather similar across follow-up. Another potential source of exposure measurement error is that modelled exposure is not necessarily a good marker for actual exposure. ${ }^{42}$ It is likely that the exposure measurement error would have led to a bias towards the null, but we have not attempted to quantify that bias. In future studies, we will have access to more detailed data on exposure to air pollution, in terms of geographical and temporal resolution and in terms of source-specific exposures.

Another strength of the study is that we have enough statistical power to analyse data in the four counties 
separately. The sometimes heterogeneous results between the areas raise important questions. For example, the risk estimates seemed generally close to one (no association) in Skåne, but were generally quite homogeneous in the other three counties. Excluding areas where air pollution levels $>15 \mu \mathrm{g} / \mathrm{m}^{3}$ (which basically means excluding the main city centres) resulted in a statistically significant $\mathrm{HR}$ associated with $\mathrm{NO}_{2}$ in Skåne of 1.16. A possible reason for the results in Skåne is that the exposure model was not as valid in Skåne as in the other counties. For example, it is known that ozone is difficult to model in Skåne, ${ }^{43}$ possibly due to local production of ozone in the summertime, which could skew the results. The discrepancy between Skåne and the other three counties could also be due to differences in terms of demography, immigration, heterogeneity in dispensed N05 between different socioeconomic groups or in associations between socioeconomy and residential air pollution levels, not fully accounted for in the statistical models. We have previously observed that patterns between socioeconomy and air pollution in Skåne seem to be complex, ${ }^{44}$ but crude analyses suggest that such patterns can also be complex in other parts of the study area.

The crude HRs were close to one, but they are not meaningful unless adjusted for age. Age, in fact, seemed to be the only variable with a substantial influence on the HRs, but potential residual confounding due to socioeconomy should nevertheless be mentioned as an alternative explanation of our findings, although an additional analysis adjusting for parental income did not change the estimates. It is important to fully adjust for socioeconomy when investigating mental health outcomes in children and adolescents. ${ }^{37}$ It should be noted that while all primary and in-patient care for children and adolescents is completely free of charge for the individual (funded by tax), medications are not free up to a certain annual amount (of around €200). Dispensation of medication is therefore more sensitive to socioeconomic status than, for example, outcomes based on hospital visits or diagnoses. Since air pollution concentrations are also associated with socioeconomic status, the importance of adjusting fully for socioeconomic status in our setting cannot be stressed enough. We used parental educational level and SAMS area educational level as main indicators for socioeconomy, and we also adjusted for body mass index and smoking during early pregnancy since those variables also capture socioeconomic status to a large extent. It would have been desirable to have other data on socioeconomy and lifestyle factors, but the data on socioeconomy are limited to what can be found in the Swedish nationwide registers. However, the HRs did not seem especially sensitive to inclusion or exclusion of the socioeconomic indicators we had access to. We therefore think that the probability for residual confounding from socioeconomy to explain our findings is rather small. Residual confounding could also be present with respect to environmental factors not accounted for in our study, for example, traffic-related noise (which hypothetically could be associated with the outcome). Unfortunately, we had no access to models on traffic-related noise, and thus could not rule out noise as an alternative explanation of our findings.

\section{Comparison to other studies and discussion of potential mechanisms}

To the best of our knowledge, this is the first study to consider the association between long-term exposure to air pollution and mental health in children. However, our findings are consistent with two prior studies of exposure to air pollution in association with anxiety, ${ }^{6}$ and perceived stress, ${ }^{7}$ in older citizens and with studies on short-term exposure to air pollution and mental health outcomes in the general population. ${ }^{8-16}$ Furthermore, there is an increasing body of evidence suggesting air pollution to be associated with cognitive development in children, ${ }^{23-25} 33$ and with autism spectrum disorder. ${ }^{26-29} 3132$

The marker for mental health in this study was dispensed N05 medications, a broad group of medications where the majority of dispensed medications are sedative medications and sleeping pills, but where also medications for children and adolescents with severe mental health problems such as schizophrenia and acute psychosis are included. It is possible that the association we observed is driven by small segments in this broad group. It is therefore somewhat difficult to speculate on possible mechanisms. Furthermore, we observed associations between dispensed $\mathrm{N} 05$ medications and also $\mathrm{NO}_{2}$ and $\mathrm{PM}_{10}$, but it was not possible to adjust the respective pollutant estimate for the other pollutant because $\mathrm{NO}_{2}$ was one of the predictors of urban background $\mathrm{PM}_{10}$ in the $\mathrm{PM}_{10}$ model. We therefore consider our results an indication for air pollution in general to be associated with dispensed N05 medications, and refrain from speculating on which specific component within the pollution mix might be driving the observed associations. Air pollution can cause inflammation and oxidative stress. ${ }^{45-47}$ It has been speculated that exposure to air pollution could induce or exacerbate anxiety (which is one of the most important patient groups who dispense N05) by increasing oxidative stress and inflammation. ${ }^{48}$ There are animal studies suggesting that oxidative stress is associated with a range of psychiatric disorders such as schizophrenia, bipolar disorder or anxiety-like behaviour, ${ }^{49-51}$ and that systemic inflammation may be associated with depressive-like/anxiety-like behaviour and memory impairment. ${ }^{51}{ }^{52}$ Furthermore, an experimental study in mice suggests that fine particulate air pollution could cause depressive-like responses and impairments in spatial learning and memory. Mice that were exposed to fine particulate matter (PM) had an elevated hippocampal pro-inflammatory cytokine expression, whereas apical dendritic spine density and dendritic branching were decreased in the hippocampal CA1 and CA3 regions. ${ }^{53}$ Oberdörster and $\mathrm{Utell}^{2}$ first suggested that the brain might be vulnerable to 
ultrafine ambient particulate matter. Biological components of particles such as endotoxins, mould and pollen have been linked to neurodevelopmental disorders (eg, schizophrenia, autism and mental retardation) and neurodegenerative diseases. ${ }^{54}$ Another theory is that air pollution acts by inducing or aggravating major medical conditions, but the study design does not fully allow for a distinction between exacerbation or incident cases. We used modelled annual mean concentrations as a marker for long-term exposure to air pollution, but it is possible that only certain exposure windows are of interest. For example, fetal life may be extra sensitive. ${ }^{55} 56$

\section{Conclusions and implications}

In Sweden, the societal cost for mental disorders has been estimated to be $2 \%$ of Gross Domestic Product (GDP). The onset is often in adolescence or young adulthood. Remission is not always possible and for many, symptoms persist despite use of treatments. If confirmed, our findings implicate that there may be a link between exposure to air pollution and dispensed medications for certain psychiatric disorders in children and adolescents.

Acknowledgements The Umeå SIMSAM Laboratory data infrastructure used in this study was developed with support from the Swedish Research Council (2008-7491) and with strategic support from Umeå University.

Contributors All authors contributed to the conception or design of the work or the acquisition, analysis, or interpretation of data for the work, and drafted the work or revised it critically for important intellectual content and gave their final approval of the version to be published and agreed to be accountable for all aspects of the work in ensuring that questions related to the accuracy or integrity of any part of the work are appropriately investigated and resolved. AO, BF and LB conceived and designed the study. $\mathrm{AO}$ acquired and analysed the data and drafted the manuscript. MS helped acquire data and created figure 1. DOÅ helped interpret the data for the work and with the statistical analysis of the data.

Funding The work was funded by Vårdalstiftelsen with the Dnr VÅ 2011-25/ 430 (AO).

Competing interests None declared.

Ethics approval The study was approved by the regional ethics board in Umeå (Dnr 2010-157-31 0̈).

Provenance and peer review Not commissioned; externally peer reviewed.

Data sharing statement No additional data are available.

Open Access This is an Open Access article distributed in accordance with the Creative Commons Attribution Non Commercial (CC BY-NC 4.0) license, which permits others to distribute, remix, adapt, build upon this work noncommercially, and license their derivative works on different terms, provided the original work is properly cited and the use is non-commercial. See: http:// creativecommons.org/licenses/by-nc/4.0/

\section{REFERENCES}

1. WHO. Burden of disease from ambient air pollution for 2012summary of results. Secondary burden of disease from ambient air pollution for 2012-summary of results. 2014. http://www.who.int/phe/ health_topics/outdoorair/databases/en/ (accessed 28 May 2016).

2. Oberdörster G, Utell MJ. Ultrafine particles in the urban air: to the respiratory tract-and beyond? Environ Health Perspect 2002;110: A440-1
3. Block ML, Elder A, Auten RL, et al. The outdoor air pollution and brain health workshop. Neurotoxicology 2012;33:972-84.

4. Evans GW, Colome SD, Shearer DF. Psychological reactions to air pollution. Environ Res 1988:45:1-15

5. Jacobs SV, Evans GW, Catalano R, et al. Air pollution and depressive symptomatology: exploratory analyses of intervening psychosocial factors. Popul Environ 1984;7:260-72.

6. Power MC, Kioumourtzoglou MA, Hart JE, et al. The relation between past exposure to fine particulate air pollution and prevalent anxiety: observational cohort study. BMJ 2015;350:h1111.

7. Mehta AJ, Kubzansky LD, Coull BA, et al. Associations between air pollution and perceived stress: the veterans administration normative aging study. Environ Health 2015;14:10.

8. Briere J, Downes A, Spensley J. Summer in the city: urban weather conditions and psychiatric emergency-room visits. J Abnorm Psychol 1983;92:77.

9. Rotton J, Frey J. Psychological costs of air pollution: atmospheric conditions, seasonal trends, and psychiatric emergencies. Popul Environ 1984;7:3-16.

10. Strahilevitz M, Strahilevitz A, Miller JE. Air pollutants and the admission rate of psychiatric patients. Am J Psychiatry 1979;136:205-7.

11. Szyszkowicz M, Willey JB, Grafstein E, et al. Air pollution and emergency department visits for suicide attempts in Vancouver, Canada. Environ Health Insights 2010;4:79-86.

12. Szyszkowicz M, Rowe BH, Colman I. Air pollution and daily emergency department visits for depression. Int J Occup Med Environ Health 2009;22:355-62.

13. Szyszkowicz M. Ambient air pollution and daily emergency department visits for ischemic stroke in Edmonton, Canada Int J Occup Med Environ Health 2008;21:295-300.

14. Kim C, Jung SH, Kang DR, et al. Ambient particulate matter as a risk factor for suicide. Am J Psychiatry 2010;167:1100-7.

15. Biermann T, Stilianakis N, Bleich S, et al. The hypothesis of an impact of ozone on the occurrence of completed and attempted suicides. Med Hypotheses 2009;72:338-41.

16. $\mathrm{Lim} \mathrm{YH}, \mathrm{Kim} \mathrm{H}, \mathrm{Kim} \mathrm{JH}$, et al. Air pollution and symptoms of depression in elderly adults. Environ Health Perspect 2012;120:1023-8.

17. Shiue I. Neighborhood epidemiological monitoring and adult mental health: European Quality of Life Survey, 2007-2012. Environ Sci Pollut Res Int 2015;22:6095-103.

18. Chen JC, Schwartz J. Neurobehavioral effects of ambient air pollution on cognitive performance in US adults. Neurotoxicology 2009;30:231-9.

19. Power MC, Weisskopf MG, Alexeeff SE, et al. Traffic-related air pollution and cognitive function in a cohort of older men. Environ Health Perspect 2011;119:682-7.

20. Weuve J, Puett RC, Schwartz J, et al. Exposure to particulate air pollution and cognitive decline in older women. Arch Intern Med 2012;172:219-27.

21. Ranft U, Schikowski T, Sugiri D, et al. Long-term exposure to traffic-related particulate matter impairs cognitive function in the elderly. Environ Res 2009;109:1004-11.

22. Suglia SF, Gryparis A, Wright RO, et al. Association of black carbon with cognition among children in a prospective birth cohort study. Am J Epidemiol 2008;167:280-6.

23. Calderón-Garcidueñas L, Solt AC, Henríquez-Roldán C, et al. Long-term air pollution exposure is associated with neuroinflammation, an altered innate immune response, disruption of the blood-brain barrier, ultrafine particulate deposition, and accumulation of amyloid $\beta-42$ and $\alpha$-synuclein in children and young adults. Toxicol Pathol 2008;36:289-310.

24. Wang S, Zhang J, Zeng X, et al. Association of traffic-related air pollution with children's neurobehavioral functions in Quanzhou, China. Environ Health Perspect 2009;117:1612-18.

25. Morales E, Julvez J, Torrent M, et al. Association of early-life exposure to household gas appliances and indoor nitrogen dioxide with cognition and attention behavior in preschoolers. $\mathrm{Am} \mathrm{J}$ Epidemiol 2009;169:1327-36.

26. von Ehrenstein OS, Aralis $\mathrm{H}$, Cockburn $\mathrm{M}$, et al. In utero exposure to toxic air pollutants and risk of childhood autism. Epidemiology 2014;:25:851-8.

27. Roberts AL, Lyall K, Hart JE, et al. Perinatal air pollutant exposures and autism spectrum disorder in the children of nurses' health study II participants. Environ Health Perspect 2013;121:978-84.

28. Becerra TA, Wilhelm M, Olsen J, et al. Ambient air pollution and autism in Los Angeles county, California. Environ Health Perspect 2013;121:380-6. 
29. Kalkbrenner AE, Daniels JL, Chen JC, et al. Perinatal exposure to hazardous air pollutants and autism spectrum disorders at age 8. Epidemiology 2010;21:631-41.

30. Windham GC, Zhang L, Gunier R, et al. Autism spectrum disorders in relation to distribution of hazardous air pollutants in the San Francisco Bay area. Environ Health Perspect 2006;114:1438-44.

31. Volk HE, Hertz-Picciotto I, Delwiche L, et al. Residential proximity to freeways and autism in the CHARGE study. Environ Health Perspect 2011;119:873-7.

32. Volk HE, Lurmann F, Penfold B, et al. Traffic-related air pollution, particulate matter, and autism. JAMA Psychiatry 2013;70:71-7.

33. Sunyer J, Esnaola M, Alvarez-Pedrerol M, et al. Association between traffic-related air pollution in schools and cognitive development in primary school children: a prospective cohort study. PLoS Med 2015;12:e1001792.

34. Guxens M, Sunyer J. A review of epidemiological studies on neuropsychological effects of air pollution. Swiss Med Wkly 2012;141:w13322.

35. Cheshire P. Segregated neighbourhoods and mixed communities: a critical analysis. York, UK: Joseph Rowntree Foundation, 2007.

36. Naess O, Piro FN, Nafstad P, et al. Air pollution, social deprivation, and mortality: a multilevel cohort study. Epidemiology 2007;18:686-94.

37. Starfield B, Riley AW, Witt WP, et al. Social class gradients in health during adolescence. J Epidemiol Community Health 2002;56:354-61.

38. Marsella AJ. Urbanization, mental health, and social deviancy: a review of issues and research. Am Psychol 1998;53:624.

39. Leventhal T, Brooks-Gunn J. Moving to opportunity: an experimenta study of neighborhood effects on mental health. Am J Public Health 2003;93:1576-82.

40. Gustafsson M, Forsberg B, Orru H, et al. Quantification of population exposure to NO2, PM2.5 and PM10 and estimated health impacts in Sweden 2010: IVL Report B 2197. Stockholm, Sweden: IVL Svenska Miljöinstitutet, 2014. http://www.ivl.se/download/18. 343dc99d14e8bb0f58b754c/1446710048540/B1792.pdf (accessed 28 May 2016).

41. Sjöberg K, Haeger-Eugensson M, Forsberg B, et al. Quantification of population exposure to nitrogen dioxide in Sweden 2005. IVL Report B 1749. Stockholm, Sweden: IVL Svenska Miljöinstitutet, 2007. http://www3.ivl.se/rapporter/pdf/B1749.pdf (accessed 28 May 2016).

42. Stroh E, Rittner R, Oudin A, et al. Measured and modeled personal and environmental NO2 exposure. Popul Health Metr 2012;10:10.
43. Malmqvist E, Olsson D, Hagenbjörk-Gustafsson A, et al. Assessing ozone exposure for epidemiological studies in Malmö and Umeå, Sweden. Atmos Environ 2014;94:241-8

44. Stroh E, Oudin A, Gustafsson S, et al. Are associations between socio-economic characteristics and exposure to air pollution a question of study area size? An example from Scania, Sweden. Int J Health Geogr 2005;4:30.

45. Chuang KJ, Chan CC, Su TC, et al. The effect of urban air pollution on inflammation, oxidative stress, coagulation, and autonomic dysfunction in young adults. Am J Respir Crit Care Med 2007;176:370-6.

46. Sun $\mathrm{Q}$, Wang $\mathrm{A}$, Jin $\mathrm{X}$, et al. Long-term air pollution exposure and acceleration of atherosclerosis and vascular inflammation in an animal model. JAMA 2005;294:3003-10.

47. Pope CA III, Hansen ML, Long RW, et al. Ambient particulate air pollution, heart rate variability, and blood markers of inflammation in a panel of elderly subjects. Environ Health Perspect 2004;112:339.

48. Hou R, Baldwin DS. A neuroimmunological perspective on anxiety disorders. Hum Psychopharmacol 2012;27:6-14.

49. $\mathrm{Ng} \mathrm{F}$, Berk M, Dean O, et al. Oxidative stress in psychiatric disorders: evidence base and therapeutic implications. Int $J$ Neuropsychopharmacol 2008;11:851-76.

50. Salim S, Sarraj N, Taneja M, et al. Moderate treadmill exercise prevents oxidative stress-induced anxiety-like behavior in rats. Behav Brain Res 2010;208:545-52.

51. Patki G, Solanki N, Atrooz F, et al. Depression, anxiety-like behavior and memory impairment are associated with increased oxidative stress and inflammation in a rat model of social stress. Brain Res 2013;1539:73-86.

52. Engler $\mathrm{H}$, Doenlen $\mathrm{R}$, Engler $\mathrm{A}$, et al. Acute amygdaloid response to systemic inflammation. Brain Behav Immun 2011;25:1384-92.

53. Fonken LK, Xu X, Weil ZM, et al. Air pollution impairs cognition, provokes depressive-like behaviors and alters hippocampal cytokine expression and morphology. Mol Psychiatry 2011;16:987-95.

54. Meyer U, Feldon J, Fatemi SH. In-vivo rodent models for the experimental investigation of prenatal immune activation effects in neurodevelopmental brain disorders. Neurosci Biobehav Rev 2009;33:1061-79.

55. Rice D, Barone S Jr. Critical periods of vulnerability for the developing nervous system: evidence from humans and anima models. Environ Health Perspect 2000;108(Suppl 3):511-33.

56. Landrigan PJ, Sonawane B, Butler RN, et al. Early environmenta origins of neurodegenerative disease in later life. Environ Health Perspect 2005;113:1230-3. 